Research Article

\title{
Estimation of Actual Evapotranspiration Distribution in the Huaihe River Upstream Basin Based on the Generalized Complementary Principle
}

\author{
Jiaqi Gao $\mathbb{D}^{1},{ }^{1}$ Miao Qiao, ${ }^{2}$ Xinfa Qiu $\left(\mathbb{D},{ }^{3}\right.$ Yan Zeng $\mathbb{D}^{4},{ }^{4}$ Huanhuan Hua, ${ }^{5}$ Xiuzhi Ye, ${ }^{6}$ \\ and Mustapha Adamu ${ }^{7}$ \\ ${ }^{1}$ College of Atmospheric Science, Nanjing University of Information Science and Technology, Nanjing 210044, China \\ ${ }^{2}$ Inner Mongolia Meteorological Information Center, Huhehot 010000, China \\ ${ }^{3}$ College of Applied Meteorology, Nanjing University of Information Science and Technology, Nanjing 210044, China \\ ${ }^{4}$ Climate Centre of Jiangsu Province, Jiangsu Provincial Meteorological Bureau, Nanjing 210009, China \\ ${ }^{5}$ Nanjing Broadcasting System, Nanjing 210001, China \\ ${ }^{6}$ Jinjiang Meteorological Bureau, Quanzhou 362200, China \\ ${ }^{7}$ College of International Students, Nanjing University of Information Science and Technology, Nanjing 210044, China
}

Correspondence should be addressed to Xinfa Qiu; xfqiu135@nuist.edu.cn

Received 2 February 2018; Revised 31 March 2018; Accepted 6 May 2018; Published 8 July 2018

Academic Editor: Hui Xu

Copyright (c) 2018 Jiaqi Gao et al. This is an open access article distributed under the Creative Commons Attribution License, which permits unrestricted use, distribution, and reproduction in any medium, provided the original work is properly cited.

\begin{abstract}
The accurate estimation of actual evapotranspiration can help improve the utilization of water resources and ease the ecological stress. Based on the generalized complementary principle proposed by Brutsaert in 2015, we used meteorological and hydrological data to estimate the actual evapotranspiration at a resolution of $1 \mathrm{~km} \times 1 \mathrm{~km}$ between the years of 1961 and 2000 and also verified the model's stability. In this study, we used the water balance equation to calibrate the parameters, coupled with the spatial simulation results of the meteorological elements in the actual evapotranspiration model. The estimation results of actual evapotranspiration show that the generalized complementary principle model had high estimation precision in this basin, with an average absolute error of $16.64 \mathrm{~mm}$ and an average relative error of $2.25 \%$. With respect to spatial distribution, the average actual evapotranspiration over the years in the basin tended to have high and low distribution in the northern and southern parts of the basin, respectively. The actual evapotranspiration in the basin showed a decreasing trend over the period, with a rate of $24.1 \mathrm{~mm} / 10$ years. Correlation coefficient analysis showed that the percentage decreases in percentage sunshine and the decreases in the daily range of temperature were the main reasons for the decrease in actual evapotranspiration.
\end{abstract}

\section{Introduction}

Evapotranspiration from the land surface plays a key role in maintaining the balance of land surface water-lakes-reservoirs and the energy balance of the earth's surface [1-4]. Evapotranspiration is a very important step in the water cycle. During the evaporation process, water is transported from the surface to the atmosphere. The water circulation, energy balance, and carbon cycle are closely linked. Many studies have shown that at least $70 \%$ of surface precipitation will return to the atmosphere through evapotranspiration, and the value that rises to over $90 \%$ in drought areas. The accurate estimation of basin evaporation has very important applications for water resources assessment, vegetation drought monitoring, and ecological water use. The complementary principle was proposed by Bouchet [1]. This model, based on the principle of complementary correlation, is widely promoted and used because it only needs conventional meteorological data as inputs to calculate evapotranspiration rather than hydrological and soil data which are hard to obtain.

Actual evapotranspiration is defined as a combined process of both evaporation from soil and plant surfaces and transpiration through plant canopies [5]. The model for estimating actual evapotranspiration based on the complementary 
principle mainly includes the following: the advection-aridity (AA) [6], the complementary relationship areal evapotranspiration (CRAE) [7], and the Granger and Gray (GG) [8] model. Jian et al. [9] applied the AA model to the Tarim River to estimate actual evapotranspiration and verified the complementary correlation theory, which proved that the calculation results of the AA model in this area are reasonable and credible. Han et al. [10] compared the applicability of the AA, GG, and PM-Katerji models, and the results showed that the AA model had good estimation ability in generally wet conditions, whereas the estimated actual evapotranspiration in dry regions was relatively low and the estimation results under very wet conditions were relatively high. The Granger model was approximately equivalent to the AA model under neither dry nor wet conditions, and the limits of variation of the evapotranspiration ratio were practical over a wide range. The PM-Katerji model had poor estimation results when the variation of the evapotranspiration ratio was larger. Han et al. [11] first proposed boundary conditions in the formulation of a complementary relationship model. Based on the model by Han et al. [11], Brutsaert [2] set physical constraints for the ratio of actual evapotranspiration to possible evapotranspiration, as well as the ratio of wet evapotranspiration to evapotranspiration, and proposed a generalized complementary correlation principle. Crago et al. [12] revised the generalized complementary principle of Brutsaert [2] and concluded that when the actual evapotranspiration was close to 0 , the ratio of wet evapotranspiration to possible evapotranspiration is not 0 , but between 0 and 1 . The revised model was tested using depth and precipitation data from the United States. Szilagyi et al. [13] took into account the limitations of water balance data and then derived a CR model without calibration that was a unique estimation Priestley-Taylor $\alpha$ parameter model with minimum data requirements and no dependencies for the calculation of the parameter $\alpha$. The works of Crago et al. [12] and Szilagyi et al. [13] have been modified and updated based on Brutsaert [2], and new uncertainties have been discussed. Studies show that models based on the principle of complementary correlation are less effective in estimating actual evapotranspiration in humid and arid environments, and actual evapotranspiration cannot be calculated in areas where drought is severe or in very humid areas. However, the principle of generalized complementary correlation does not have this limitation.

Water resources per unit area and per capita in China are below the world average, and freshwater resources per capita in China are only a quarter of the world's per capita freshwater resources. The distribution of water resources in China is extremely uneven, and the evapotranspiration process is an important process of the water cycle. The accurate estimation of evapotranspiration has a very important value for water resources assessment and vegetation drought monitoring. In China, scarcely any research has been done based on the principle of generalized complementary correlation. In this study, we selected the basin above Wangjiaba in the upper Huaihe River as the study area and calculated the annual evapotranspiration over 40 years according to the generalized complementary principle of Brutsaert [2] using spatial simulation results of meteorological elements; we then verified the simulation accuracy of the actual evapotranspiration in the basin. Regarding the determination of model parameters and basic data inputs, the simulation results for evapotranspiration in different regions were different. Research on the coupling of spatial simulation methods of meteorological elements with an actual evapotranspiration model was also an important purpose of this study.

\section{Data and Methods}

2.1. Data. The Huaihe River Basin is in eastern China between the Yangtze River and the Yellow River. The Huaihe River is divided into three parts: the upper, middle, and lower reaches. The upper reach is Honghekou and above and is $360 \mathrm{~km}$ long between longitudes $113^{\circ} 27^{\prime}$ and $115^{\circ} 62^{\prime} \mathrm{E}$ and latitudes $31^{\circ} 47^{\prime}$ and $33^{\circ} 53^{\prime} \mathrm{N}$. The watershed control area is approximately $31,000 \mathrm{~km}^{2}$. The Huaihe River Basin is in the transitional climate zone between North China and South China and is characterized by a warm temperate and semihumid monsoon climate. Additionally, the winter and spring are characterized by droughts with rare rainfall, and the summer and autumn are usually hot with frequent rain. The rainfall in the basin is sufficient, and the annual average rainfall is approximately $920 \mathrm{~mm}$. The spatial distribution of rainfall roughly decreases from the south to the north, with the mountainous areas receiving more rain than the plains areas. The annual average temperature is generally $11-16^{\circ} \mathrm{C}$, and the monthly average temperature of July is the highest, usually approximately $25^{\circ} \mathrm{C}$. The monthly average temperature of January is the lowest, usually approximately $0{ }^{\circ} \mathrm{C}[14]$. In this study, we chose the upper reach of the Huaihe River Basin as a research area not only because we have sufficient historical meteorological data for this area but also because the climate characteristics of this area represent the transitional climate between China's north and south. Figure 1 shows the distribution of the water system, meteorological stations, and hydrological stations in the upper reach of the Huaihe River Basin and its surrounding areas.

The meteorological data between 1956 and 2000, which were obtained from the National Meteorological Information Center, include the daily average temperature, daily minimum temperature, daily maximum temperature, daily range of temperature, percentage sunshine, daily average wind speed, and daily precipitation data. The level-2 water resources data were obtained from the Water Resources, Hydropower Planning and Design Institute of the Ministry of Water Resources. The level-2 river network data and the digital elevation model (DEM) data source were derived from the National Geomatics Center of China. We estimated the distributed results of the monthly albedo from 1961 to 2000 using the data from NOAA/AVHRR satellite channels 1 and 2 from 1961 to 2000 and the estimation formula for the surface albedo.

\subsection{Methods}

2.2.1. Estimation of Actual Evapotranspiration. In this study, the actual evapotranspiration is calculated based on the generalized complementary principle proposed by Brutsaert. He introduced nondimensional $E_{\mathrm{TW}}$ and $E_{\mathrm{TA}}$ via dividing 


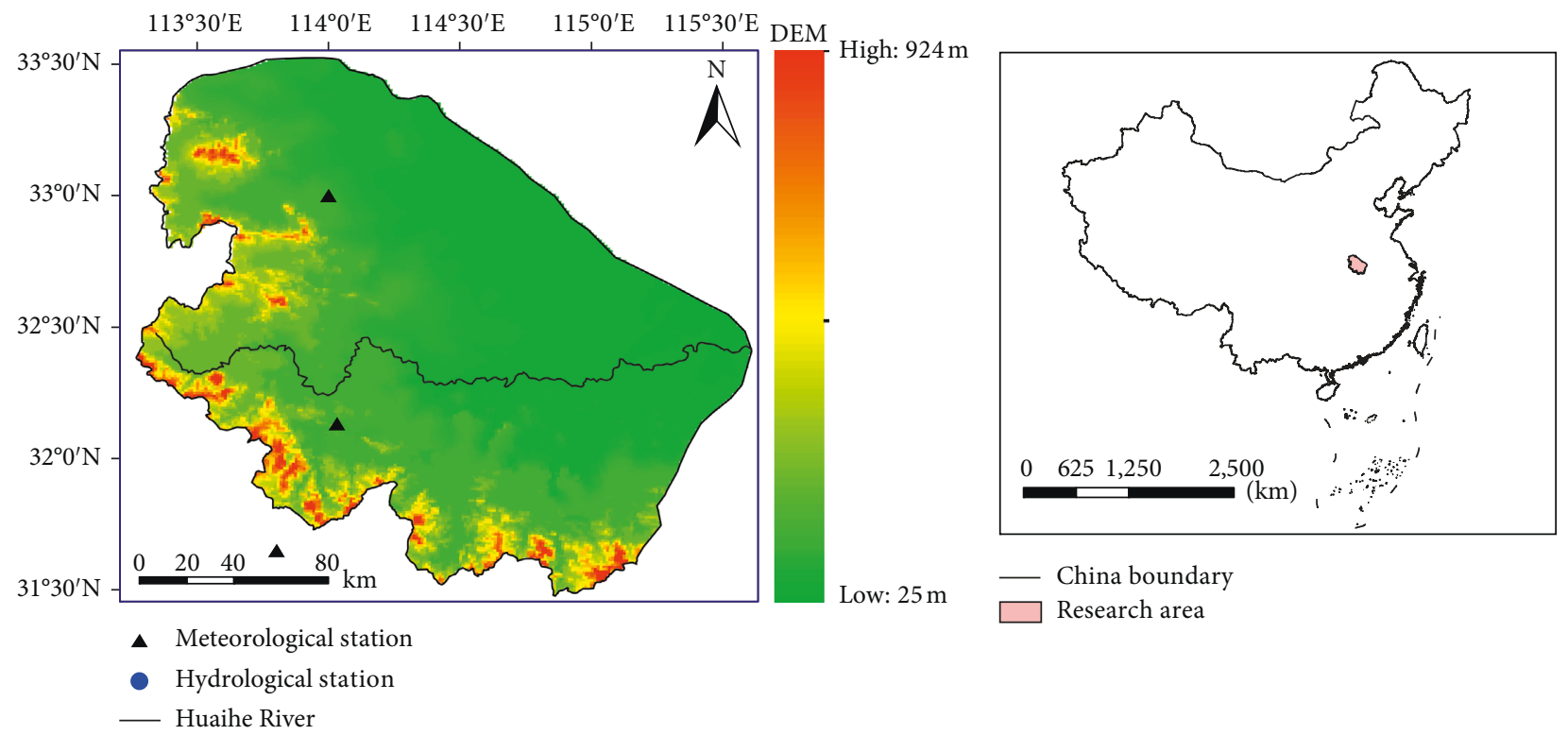

FIGURE 1: Distribution of the water system, meteorological stations, and hydrological stations in the upper reach of the Huaihe River Basin and its surrounding areas.

them by $E_{\mathrm{TP}}, x=E_{\mathrm{TW}} / E_{\mathrm{TP}}$, and $y=E_{\mathrm{TA}} / E_{\mathrm{TP}}$, where $E_{\mathrm{TA}}$ represents the actual evapotranspiration, $E_{\mathrm{TP}}$ represents the potential evapotranspiration, and $E_{\mathrm{TW}}$ represents the wet potential evapotranspiration under the "potential" conditions that the evapotranspiration water is not a limiting factor with the same solar radiation input and the same meso-alpha scale pressure gradient pattern [2].

The polynomial implementation can be written by expressing the relationship of $x$ and $y$ as follows:

$$
y=x-\sum_{i=0}^{n} a_{i} x^{i}
$$

where $a_{i}$ is a coefficient and $n$ is the degree of the polynomial.

To develop a significant equation, Brutsaert [2] imposed four physically determined boundary conditions that he used with (1) to develop a fourth-order polynomial solution. Specifically, he made the following assumptions:
(i) $y=1, x=1$,
(ii) $y=0, x=0$,
(iii) $d y / d x=1, x=1$,
(iv) $d y / d x=0, x=0$.

Under very moist conditions, (i) shows that $y=1$ as $x=$ 1 and $a_{0}=0, a_{1}=1, a_{2}=-2$, and $a_{3}=1$; this yields the main result:

$$
y=2 x^{2}-x^{3}
$$

or in the equation with the original variables:

$$
E_{\mathrm{TA}}=\left(\frac{E_{\mathrm{TW}}}{E_{\mathrm{TP}}}\right)^{2}\left(2 E_{\mathrm{TP}}-E_{\mathrm{TW}}\right),
$$

where $E_{\mathrm{TW}}$ is given by the Priestley and Taylor [15] equation and $E_{\mathrm{TP}}$ by the Penman $[15,16]$ equation. That is,

$$
E_{\mathrm{TW}}=\alpha \frac{\Delta}{\Delta+\gamma}\left(R_{\mathrm{n}}-G\right),
$$

where $\alpha$ is the Priestley-Taylor parameter, related to the underlying surface conditions (here, we assume $0.72 \leq \alpha \leq 1.57$ ); $R_{\mathrm{n}}$ is the net radiation $(\mathrm{mm} / \mathrm{d}) ; G$ is the heat flux into the ground $(\mathrm{mm} / \mathrm{d})$; and $\Delta$ is the slope of the saturation vapor pressure curve $(\mathrm{hPa})$. Additionally,

$$
E_{\mathrm{TP}}=\frac{\Delta}{\Delta+\gamma}\left(R_{\mathrm{n}}-G\right)+\frac{\gamma}{\Delta+\gamma} E_{\mathrm{a}},
$$

where $\gamma$ is the psychrometric constant and $E_{\mathrm{a}}$ is the drying power of the air in $\mathrm{mm} / \mathrm{d}$.

The actual evapotranspiration can be expressed by (4) and (5) as follows:

$$
E_{\mathrm{TA}}=\alpha^{2} \frac{\Delta}{\Delta+\gamma}\left(R_{\mathrm{n}}-G\right) \frac{\left[(2-\alpha)+2(\gamma / \Delta) E_{\mathrm{a}} /\left(R_{\mathrm{n}}-G\right)\right]}{\left[1+(\gamma / \Delta) E_{\mathrm{a}} /\left(R_{\mathrm{n}}-G\right)\right]^{2}} .
$$

Since the formula [17] is based on the assumption that there is no advection, the inhomogeneity of the underlying surface of the basin will lead to the occurrence of advection. There can be no full advection in the actual environment, and $\alpha$ thus has great variability [18] and needs to be calibrated. Based on previous studies [19], the actual evapotranspiration calculated by the water balance equation (7) is calibrated with steps of 0.01 in the model's $\alpha$, which increases from 0.72 to 1.57 [20], depending on different surface conditions. The actual evapotranspiration is calculated with (6). Figure 2 shows a flow chart of the spatial distribution result of actual evapotranspiration based on the generalized complementary principle. The actual evapotranspiration is calculated from the water balance method as follows [17]: 


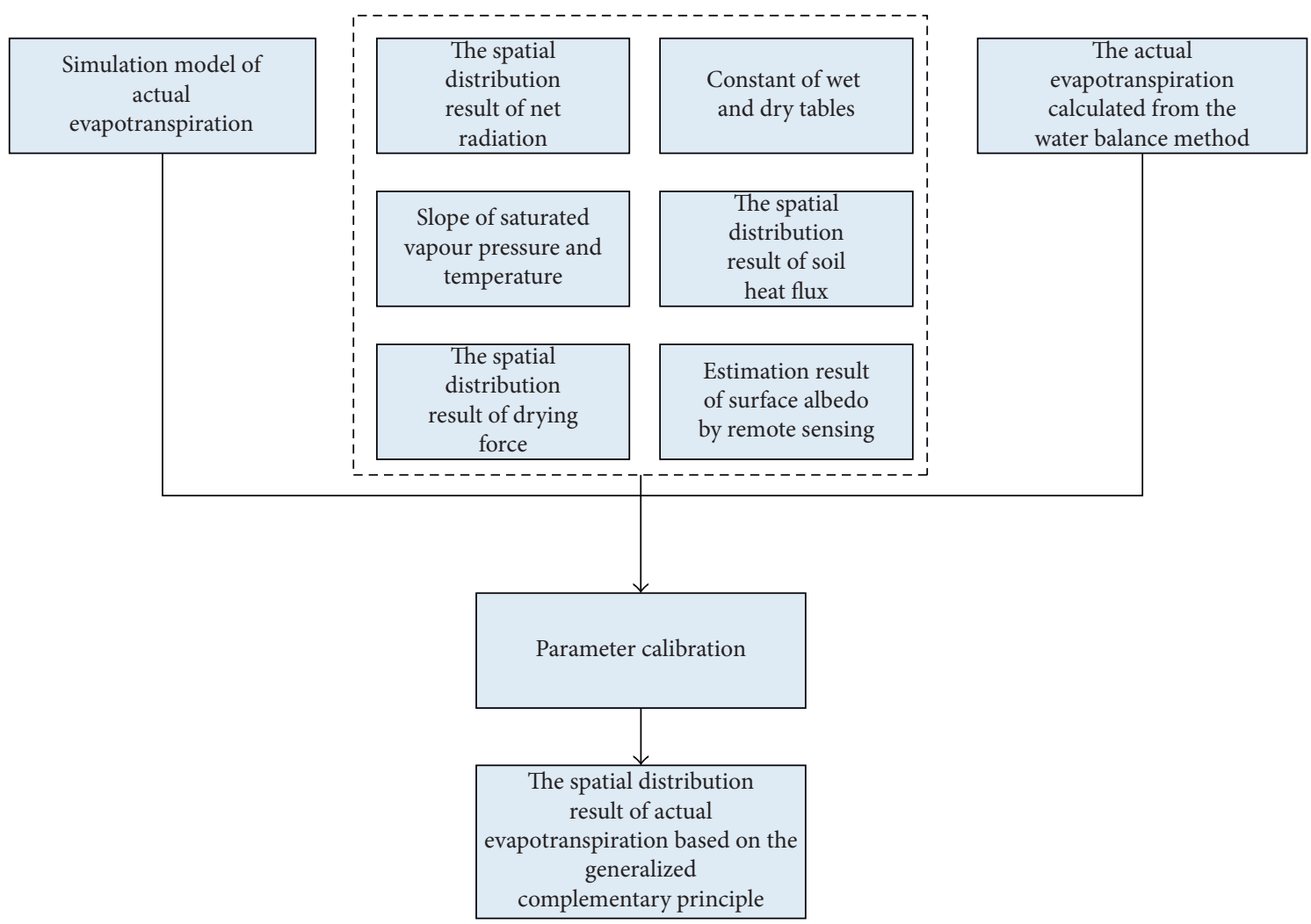

Figure 2: Flow chart of the spatial distribution result of actual evapotranspiration based on the generalized complementary principle.

$$
E_{\mathrm{TA}}=P-R \pm \Delta W
$$

where $P$ is the average precipitation in the basin; $R$ is the runoff depth in the basin; and $\Delta W$ is the changing value of soil water storage in the basin, averaged for many years; the changing value of soil water storage in the basin is approximately zero.

\subsubsection{Calculation of Model Components}

(1) Slope of the Saturation Vapor Pressure Curve. The equation for calculating the slope of the saturation vapor pressure curve is given as follows [21]:

$$
\Delta=\frac{d e^{*}}{d T}=\frac{a b e^{*}}{(T+b)^{2}},
$$

where $T$ is the temperature in ${ }^{\circ} \mathrm{C}, e^{*}$ is the saturated vapor pressure (hPa), and $a$ and $b$ are coefficients. $a=17.23$ and $b=237.3$ at $T \geq 0^{\circ} \mathrm{C}$, and $a=21.88$ and $b=265.5^{\circ} \mathrm{C}$ at $\mathrm{T}<0^{\circ} \mathrm{C}$.

(2) Psychrometric Constant. The expression of psychrometric constants is defined as follows [15]:

$$
\gamma= \begin{cases}0.665 \times 10^{-3} p, & T \geq 0 \\ 0.578 \times 10^{-3} p, & T<0,\end{cases}
$$

where $T$ is the temperature in ${ }^{\circ} \mathrm{C}$ and $p$ is the vapor pressure (hPa).
(3) Net Radiation. The expression of net radiation under the complex terrain is defined [4] as follows:

$$
R_{\mathrm{n}}=Q_{\alpha \beta}\left(1-\alpha_{s}\right)-F_{\alpha \beta} \text {, }
$$

where $Q_{\alpha \beta}$ is the total radiation under the complex terrain $\left(\mathrm{MJ} /\left(\mathrm{m}^{2} \cdot \mathrm{d}\right)\right), \alpha_{\mathrm{s}}$ is the surface albedo, and $F_{\alpha \beta}$ is the net surface longwave radiation (NSLR) $\left(\mathrm{MJ} /\left(\mathrm{m}^{2} \cdot \mathrm{d}\right)\right)$. The unit needs to be unified in the calculation, with $1 \mathrm{~mm} / \mathrm{d}=$ $0.408 \mathrm{MJ} /\left(\mathrm{m}^{2} \cdot \mathrm{d}\right)$ at $T \geq 0^{\circ} \mathrm{C}$ and $1 \mathrm{~mm} / \mathrm{d}=0.355 \mathrm{MJ} /\left(\mathrm{m}^{2} \cdot \mathrm{d}\right)$ at $\mathrm{T}<0^{\circ} \mathrm{C}$.

(1) Calculation of total radiation under the complex terrain

The method of calculating the total solar radiation received by the surface under the complex terrain is as follows:

$$
Q_{\alpha \beta}=Q_{b \alpha \beta}+Q_{d \alpha \beta}+Q_{r \alpha \beta} \text {, }
$$

where $Q_{b \alpha \beta}$ is the direct solar radiation energy under the complex terrain $\left(\mathrm{MJ} /\left(\mathrm{m}^{2} \cdot \mathrm{d}\right)\right), Q_{d \alpha \beta}$ is the solar scattered radiation energy under the complex terrain $\left(M J /\left(m^{2} \cdot d\right)\right)$, and $Q_{r \alpha \beta}$ is the solar shortwave radiation reflected from the topography around the complex terrain $\left(\mathrm{MJ} /\left(\mathrm{m}^{2} \cdot \mathrm{d}\right)\right)$. For the specific calculation formula of $Q_{b \alpha \beta}, Q_{d \alpha \beta}$, and $Q_{r \alpha \beta}$, see the study by Zeng [22].

(2) Estimation of the surface albedo by remote sensing

The surface albedo can be calculated by climatological calculation or satellite remote sensing inversion. The surface albedo of this study is calculated by the method given by 
TABLE 1: Simulation parameters of net surface longwave radiation.

\begin{tabular}{ccccccccccccc}
\hline $\mathrm{P}$ & 1 & 2 & 3 & 4 & 5 & 6 & 7 & 8 & 9 & 10 & 11 \\
\hline$a_{0}$ & 0.447 & 0.473 & 0.522 & 0.577 & 0.642 & 0.691 & 0.705 & 0.661 & 0.554 & 0.497 & 0.45 & 0.438 \\
$a_{1}$ & -0.042 & -0.04 & 0.049 & -0.065 & -0.073 & -0.085 & -0.088 & -0.083 & -0.068 & -0.058 & -0.047 & -0.044 \\
$b_{0}$ & 0.201 & 0.16 & 0.16 & 0.171 & 0.101 & 0.152 & 0.123 & 0.128 & 0.211 & 0.184 & 0.173 & 0.199 \\
\hline
\end{tabular}

TABLe 2: Estimation error of actual evapotranspiration in the upper reach of the Huaihe River Basin.

\begin{tabular}{lcccc}
\hline Validation period & Water balance $(\mathrm{mm})$ & Estimated result $(\mathrm{mm})$ & Absolute error $(\mathrm{mm})$ & Relative error $(\%)$ \\
\hline $1967-1977$ & 746.16 & 716.16 & 30 & 4.02 \\
$1968-1978$ & 713.62 & 715.9 & 2.28 & 0.32 \\
$1969-1979$ & 733.71 & 716.08 & 17.63 & 2.4 \\
\hline
\end{tabular}

Valiente [23], by using the NOAA/AVHRR channel 1 and 2 data.

The surface albedo inversion is calculated using monthly measurements over the 1961-2000 period [23]. The surface albedo is mainly used to calculate the simulation parameters of the net radiation in the model. Previous studies [24, 25] carried out the calculations using some fixed values added to the net radiation model. For example, the albedo of the water surface is 7 , the albedo of the grassland is 15 , and the desert albedo is 28 . The addition of the surface albedo using remote sensing makes the spatial distribution of net radiation finer. The spatial resolution is $8 \mathrm{~km}$ :

$$
\alpha_{\mathrm{s}}=0.545 P_{\mathrm{CH} 1}+0.320 P_{\mathrm{CH} 2}+0.035 \text {, }
$$

where $\alpha_{\mathrm{s}}$ is the average monthly surface albedo and $P_{\mathrm{CH} 1}$ and $P_{\mathrm{CH} 2}$ are the results of the AVHRR channels 1 and 2, respectively.

\section{(3) Calculation of NSLR under the complex terrain}

The NSLR under the complex terrain is calculated as follows [26]:

$$
F_{\alpha \beta}=\varepsilon_{\mathrm{s}} \sigma T^{4}\left(a_{0}+a_{1} \sqrt{e}\right)\left[b_{0}+\left(1-b_{0}\right) S\right],
$$

where $\varepsilon_{\mathrm{s}}$ is the surface emissivity, generally taken as $0.95 ; \sigma$ is the Stefan-Boltzmann constant $\left(4.9 \times 10^{-9} \mathrm{MJ} /\left(\mathrm{m}^{2} \cdot \mathrm{d} \cdot \mathrm{K}\right)\right)$; $T$ is the temperature $(\mathrm{K}) ; a_{0}, a_{1}$, and $b_{0}$ are the coefficients; $e$ is the actual vapor pressure $(\mathrm{hPa})$; and $S$ is the percentage sunshine. The simulation parameters of NSLR are shown in Table 1.

(4) Soil Heat Flux. The equation for estimating the soil heat flux $G$ is defined as follows [15]:

$$
G=0.07\left(T_{i+1}-T_{i-1}\right),
$$

where $G$ is the soil heat flux $\left(\mathrm{MJ} /\left(\mathrm{m}^{2} \cdot \mathrm{d}\right)\right), T_{i+1}$ is the monthly average temperature of the next month $\left({ }^{\circ} \mathrm{C}\right)$, and $T_{i-1}$ is the monthly average temperature of the previous month $\left({ }^{\circ} \mathrm{C}\right)$.

The units need to be unified when calculating $G$, with $1 \mathrm{~mm} / \mathrm{d}=0.408 \mathrm{MJ} /\left(\mathrm{m}^{2} \cdot \mathrm{d}\right)$ at $T \geq 0^{\circ} \mathrm{C}$ and $1 \mathrm{~mm} / \mathrm{d}=$ $0.355 \mathrm{MJ} /\left(\mathrm{m}^{2} \cdot \mathrm{d}\right)$ at $T<0^{\circ} \mathrm{C}$.

(5) Drying Power. The drying power is defined as the value of the evaporation rate from open water, obtained by using the equation of saturation vapor pressure at surface and air temperatures [15]. The expression for estimating the drying power $E_{\mathrm{a}}$ is as follows $[4,15,16]$ :

$$
E_{\mathrm{a}}=0.26\left(1+0.54 u_{2}\right)\left(e^{*}-e\right),
$$

where $u_{2}$ is 2 -meter average wind speed in $\mathrm{m} / \mathrm{s}$. In this study, meteorological data generally only provide the wind speed at 10 meters from the surface, and the wind speed thus needs to be changed. The conversion formula is defined as follows [21]:

$$
u_{2} \approx 0.748 u_{10} \text {. }
$$

\section{Results}

3.1. Verification. The first evaluation of water resources in China occurred from 1956 to 1979, and a large number of reservoirs were built after 1980 . These greatly affected the water balance and are not conducive to estimating the actual evapotranspiration in the river basin. Therefore, the data from 1956 to 1976 were chosen for estimation. The $\alpha$ in the upper Huaihe River Basin is 1.25. When using multiyear average data, another method of calculating the actual evapotranspiration from (7) can be used to determine that the changing value of soil water storage in the basin is approximately zero. The methods of this study can determine the actual evapotranspiration for each year. To verify the correctness of the actual evapotranspiration using these methods, we used the water balance equation (7) in the verification component of this study to calculate the actual evapotranspiration method for comparison. Due to the limited data and the necessity for verification, we chose the 10-year moving average method, which calculated the actual evapotranspiration using the annual average data from 1967 to 1977,1968 to 1978, and 1969 to 1979 . We chose the 10 -year average to calculate the actual evapotranspiration by referring to the Priestley and Taylor [17] method, which mainly considered the stability of the calculation results. Table 2 shows the verification results. The average absolute error is $16.64 \mathrm{~mm}$, the relative error is within $\pm 5 \%$, the average bias is $9.57 \mathrm{~mm}$, the root-meansquared error (RMSE) is $20.13 \mathrm{~mm}$, and the average relative error is $2.25 \%$. The $R$-square of validation is 0.986 (Figure 3 ). Figure 3 is a square graph of water balance and generalized complementary simulation and shows their bias by the square axis and 45-degree line. 


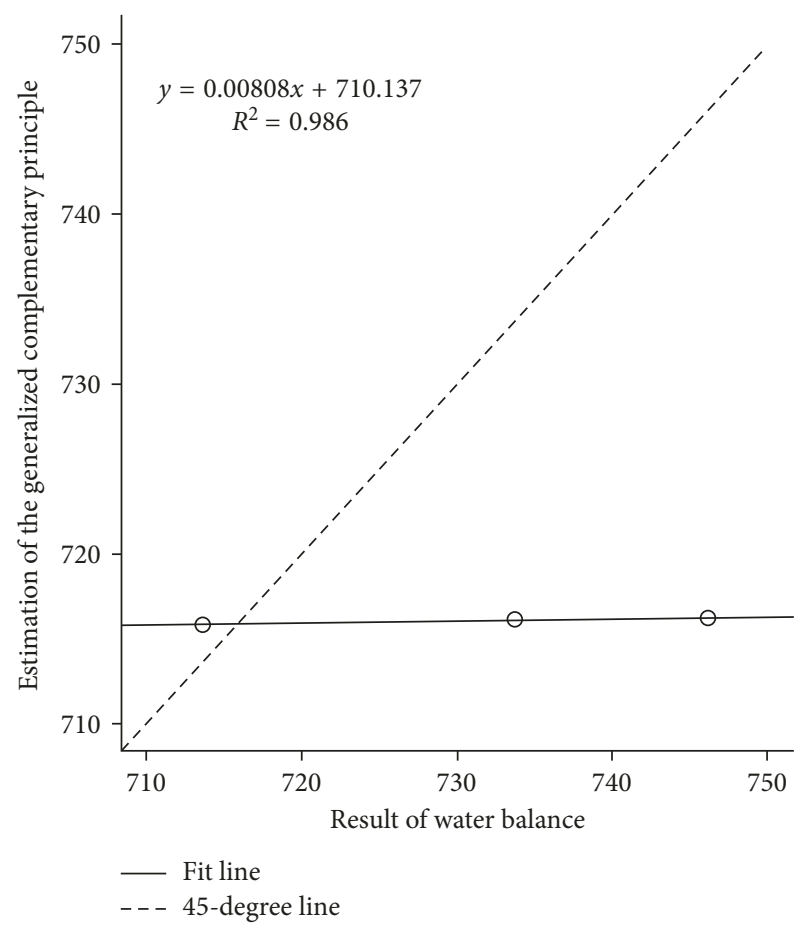

FIgURE 3: Regression plot of water balance and generalized complementary simulation using the $R$-square.

3.2. Spatial Estimation Results of Actual Evapotranspiration. Based on the simulation method in this study, we obtained the spatial distribution of annual average actual evapotranspiration in the upper reach of the Huaihe River Basin from 1961 to 2000 (Figure 4). The annual average actual evapotranspiration in the Huaihe River Basin is high in the south and low in the north. The high evapotranspiration values are concentrated in the southwest of the basin, with the highest values within the vicinity of the Dabie Mountains and the low values in the northwest watershed. The average annual evapotranspiration of the whole basin over 40 years is $665.11 \mathrm{~mm}$, and that of the water balance data is $677.38 \mathrm{~mm}$, which is consistent by an order of magnitude. The absolute error is $12.27 \mathrm{~mm}$, and the relative deviation is $1.81 \%$. These verification results illustrate the applicability of the generalized complementary correlation principle in the region. Figure 4 shows the annual average change curve of actual evapotranspiration in the upper reach of the Huaihe River Basin from 1961 to 2000. Figure 5 shows that the actual evapotranspiration is a significant downward trend over time, with a rate of decline of $24.1 \mathrm{~mm} / 10$ years.

3.3. Analysis of Influencing Factors. Pearson correlations between actual evapotranspiration and the percentage sunshine, maximum temperature, minimum temperature, average temperature, daily temperature, 2-meter average wind speed, relative humidity, daily range of temperature, actual vapor pressure, and other variables are shown in Table 3. As seen from the table, the percentage sunshine, maximum temperature, daily range of temperature, 2-meter average wind speed, and actual evapotranspiration were

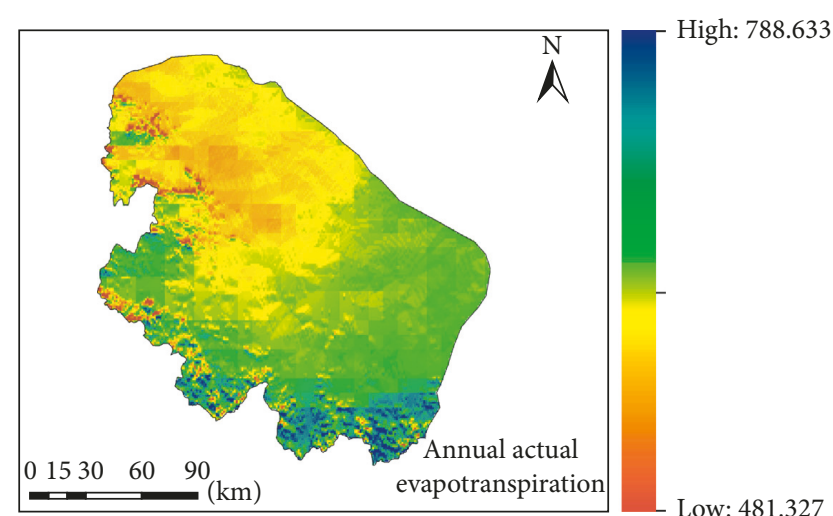

Figure 4: Spatial distribution of annual actual evapotranspiration in the upper reach of the Huaihe River Basin for the period 1961-2000.

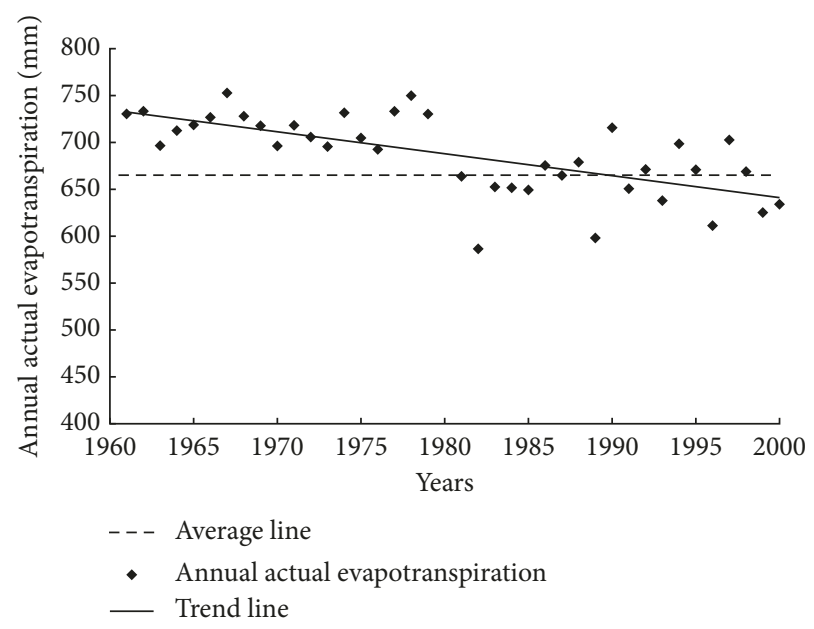

FIGURE 5: Variation of annual actual evapotranspiration in the upper reach of the Huaihe River Basin during 1961-2000.

positively correlated, and they all passed the 0.05 significance test. Therefore, we mainly analyzed the influence of the percentage sunshine, maximum temperature, daily range of temperature, and 2-meter average wind speed on the actual evapotranspiration. The $t$-test was carried out on the trend of the percentage sunshine, maximum temperature, daily range of temperature, and 2-meter average wind speed, and the test passed the significance test at the $99 \%$ confidence level. As seen from Table 3 and Figure 6, the decrease in the percentage sunshine (a), the decrease in the daily range of temperature (c), and the decrease in the 2-meter average wind speed (d) are the main reasons for the decrease of actual evapotranspiration. The increase in the maximum temperature (b) also slows down the downward trend of the actual evapotranspiration.

\section{Discussion}

In this study, we estimated actual evapotranspiration based on the generalized complementary principle. The model components (drying power, soil heat flux, net radiation, constant of wet and dry tables, etc.) and surface albedo all 
TABLE 3: Correlation coefficients between meteorological factors and actual evapotranspiration.

\begin{tabular}{|c|c|c|c|c|c|c|c|c|}
\hline & $\begin{array}{l}\text { Percentage } \\
\text { sunshine }\end{array}$ & $\begin{array}{l}\text { Relative } \\
\text { humidity }\end{array}$ & $\begin{array}{l}\text { Maximum } \\
\text { temperature }\end{array}$ & $\begin{array}{l}\text { Minimum } \\
\text { temperature }\end{array}$ & $\begin{array}{c}\text { Average } \\
\text { temperature }\end{array}$ & $\begin{array}{c}\text { Daily range of } \\
\text { temperature }\end{array}$ & $\begin{array}{l}\text { Actual vapor } \\
\text { pressure }\end{array}$ & $\begin{array}{l}\text { 2-meter average } \\
\text { wind speed }\end{array}$ \\
\hline $\begin{array}{l}\text { Actual } \\
\text { evapotranspiration }\end{array}$ & $0.771^{* *}$ & -0.292 & $0.337^{*}$ & -0.185 & 0.1 & $0.557^{* *}$ & -0.019 & $0.328^{*}$ \\
\hline
\end{tabular}

${ }^{*}$ Significant correlation at the 0.05 level; ${ }^{* *}$ Significant correlation at the 0.01 level.

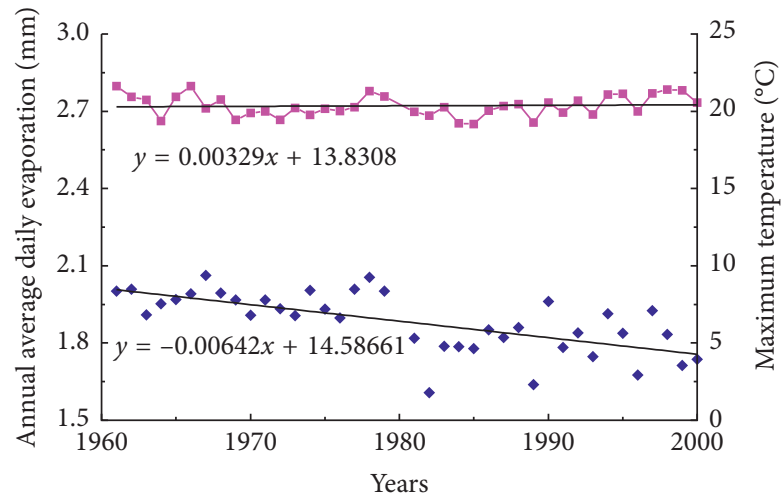

- Annual average daily evaporation - Maximum temperature

(a)

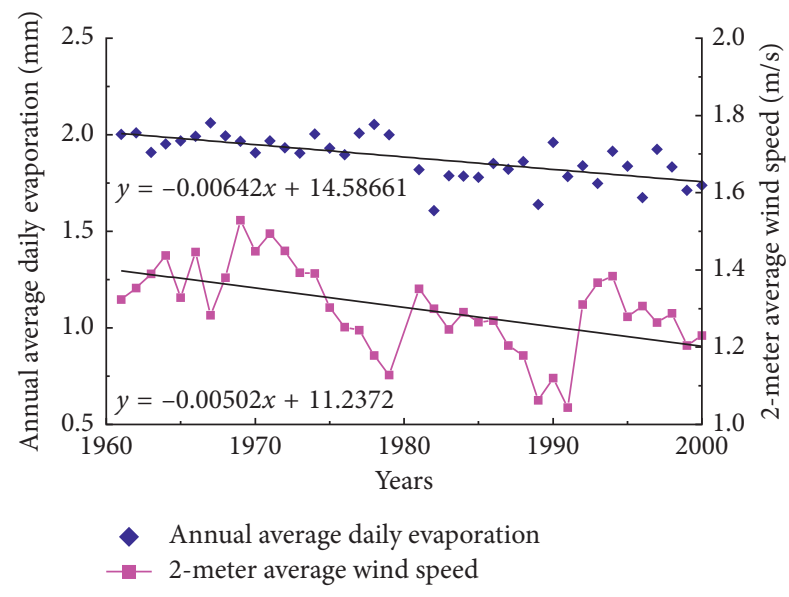

(c)

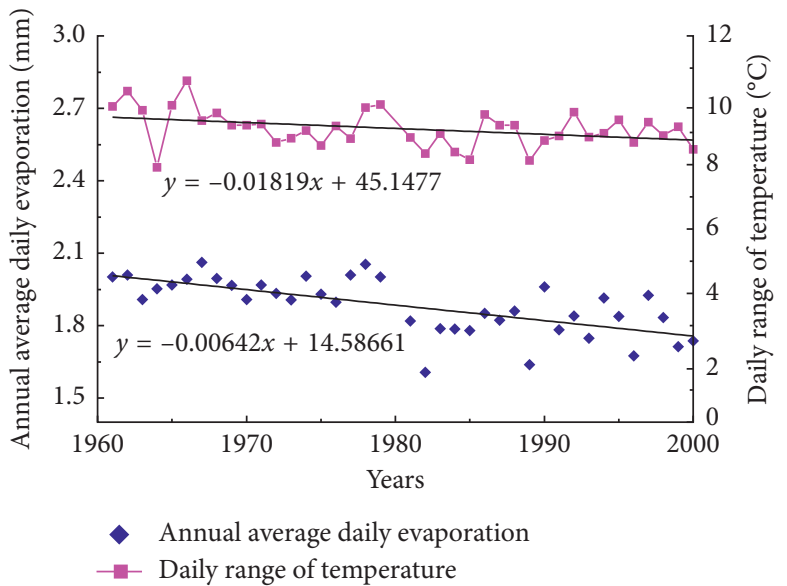

(b)

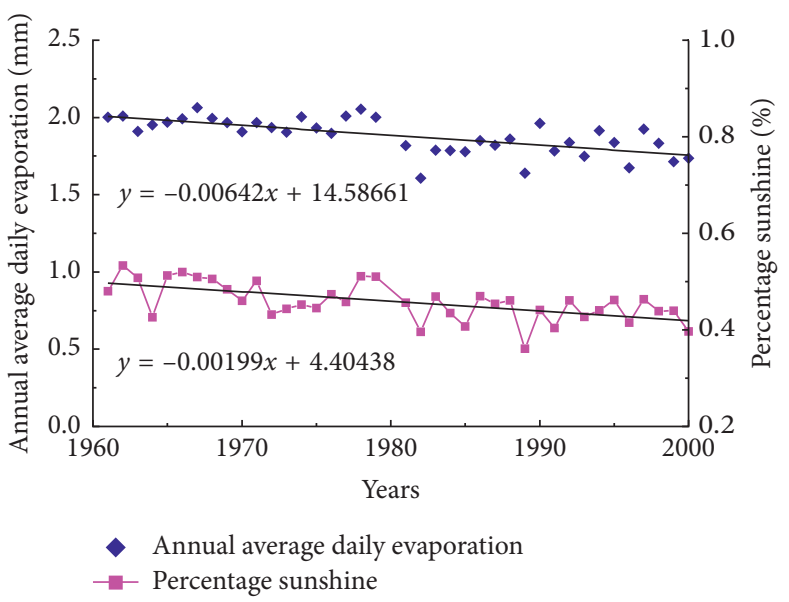

(d)

Figure 6: Variation trend graphs of maximum temperature, daily range of temperature, 2-meter average wind speed, and percentage sunshine with actual evapotranspiration.

affect the accuracy of the actual evapotranspiration. Using the Priestley-Taylor formula as a possible evapotranspiration formula, the parameter $\alpha$ is rated based on the influence of underlying surface factors. However, the $\alpha$ value changes as the range of the underlying surface changes. The smaller the calibration area, the more accurate the $\alpha$ parameter and the more reliable the possible evapotranspiration. The most accurate calibration method for the $\alpha$ parameter is a comparison of the estimation results with the measured data. The method of obtaining the actual evapotranspiration through the lysimeter is the only method that is closest to the true value; however, the lysimeter data for China are still scarce at large scales [27] and further development and study are needed. To ascertain whether the generalized complementary theory is applicable to other basins in China, further research and verification are needed.

Since the formula is based on the assumption that there is no advection, the inhomogeneity of the underlying surface of the basin will lead to the occurrence of advection. There can be no full advection in the actual environment; thus, the $\alpha$ parameter has great variability [18], and estimating it accurately requires calibration. Eagleson [18] provided values from 0.72 to 1.57 that depended on different surface conditions. Relying on instruments for observation is the most reliable way to obtain continuous evapotranspiration data. As the Chinese economy develops, more evapotranspiration instruments will be deployed. The verification part of this study could only be carried out using the water 
Table 4: Sensitivity level.

\begin{tabular}{lc}
\hline Sensitivity coefficient & Sensitivity levels \\
\hline $0.00 \leq|S|<0.05$ & Small to negligible \\
$0.05 \leq|S|<0.20$ & Medium \\
$0.20 \leq|S|<1.00$ & High \\
$|S| \geq 1.00$ & Very high \\
\hline
\end{tabular}

TABLE 5: Sensitivity of actual evapotranspiration to other variables.

\begin{tabular}{lcc}
\hline Variables & $\begin{array}{c}\text { Sensitivity } \\
\text { coefficient } S\end{array}$ & Sensitivity levels \\
\hline Slope of the saturation & 0.365 & High \\
vapor pressure curve & -0.352 & High \\
Psychrometric constant & 0.999 & High \\
Net radiation & -0.001 & Small to negligible \\
Soil heat flux & 0.000 & Small to negligible \\
Drying power & & \\
\hline
\end{tabular}

balance method, and the data were limited. In the near future, evapotranspiration measured by instruments will be used to verify the results and will make the results more reliable.

The sensitivity coefficient is a dimensionless index $S$ calculated by the radio of the change in output to input on the condition that the other variables remain constant. The sensitivity of dependent $E_{\mathrm{TA}}$ to a particular independent $X$ (slope of the saturation vapor pressure curve, psychrometric constant, net radiation, soil heat flux, or drying power) can be calculated from the derivative of $E_{\mathrm{TA}}$ with $X, \partial E_{\mathrm{TA}} / \partial X$ $[28,29]$. The first-order Taylor series approximation was applied to calculate $S$ [30-32]. To more clearly assess the sensitivity, $S$ was ranked into four classes [31] (Table 4). The higher the sensitivity coefficient value, the more the impact of this variable on evapotranspiration. The sign of $S$ determines if the model would react codirectionally to the input parameter change, that is, an increase (a decrease) of the parameter would lead to an increase (a decrease) of the output variable. Table 5 shows that the sensitivity coefficient of the variables is different and $R_{\mathrm{n}}>\Delta>\gamma>G>E_{\mathrm{a}}$. The sensitivity levels of the net radiation, slope of the saturation vapor pressure curve, and psychrometric constant are high, which indicates high sensitivity. The sensitivity impact of the slope of the saturation vapor pressure curve and net radiation is codirectional.

Many researchers $[12,13]$ have attempted to correct Brutsaert et al.'s [2] generalized complementary correlation principle. Crago et al. [12] rescaled the $x$-axis by calculation and proposed a new version of the general CR. They also believed that the new version of the general CR better predicted the overall measured actual evapotranspiration than did Brutsaert's [2] equation and maintained considerable continuity with the reasoning behind the general CR derived by Brutsaert et al. [2]. Szilagyi et al. [13] introduced a novel approach to calculate the value of the PriestleyTaylor parameter and made a new version of the CR equation with free calibration. The objective of this study was to apply the generalized complementary principle to evapotranspiration estimation at the watershed level in
China and to verify its viability. New methods $[12,13]$ have been introduced and have brought new uncertainties, which require further discussion. In our future research, we will focus on different updated CR models based on Brutsaert et al.'s [2] method and choose the best performance for one or some Chinese basins.

\section{Conclusions}

The theoretical model of the generalized complementary correlation principle was used to calculate the actual evapotranspiration using the spatial simulation results of meteorological elements in the upper reach of the Huaihe River. Estimation was successful, and the spatial distribution of the average actual evapotranspiration was well characterized by the distributed simulation. The estimated average annual evapotranspiration absolute error was $16.64 \mathrm{~mm}$, and the average relative error was $2.25 \%$. Pearson's correlation coefficient analysis showed that the reduction in the percentage sunshine and the decreases in the daily range of temperature and 2-meter average wind speed were the main reasons for the decrease in actual evapotranspiration. Therefore, for vegetation and drought monitoring and ecological modeling, estimating evapotranspiration and evaluating water resources in the basin are very important.

\section{Data Availability}

The data used to support the findings of this study are available from the corresponding author upon request.

\section{Conflicts of Interest}

The authors declare that there are no conflicts of interest regarding the publication of this article.

\section{Acknowledgments}

This work was supported by the National Natural Science Foundation of China Project (41330529). The meteorological data between 1956 and 2000 could be obtained from the China Meteorological Data Service Center (CMDSC) at http://data.cma.cn/data/cdcindex/cid/6d1b5efbdcbf9a58.html. The NOAA/AVHRR channel 1 and 2 data products could be obtained from the United States Geological Survey (USGS) at https://earthexplorer.usgs.gov. The DEM data could be obtained from the National Geomatics Center of China (NGCC) at http://www.ngcc.cn. The level-2 water resources data could be obtained from the China Renewable Energy Engineering Institute (CREEI) at http://www.creei.cn/portal/ index/index.html.

\section{References}

[1] R. J. Bouchet, "Evapotranspiration réelle et potentielle, signification climatique," International Association of Hydrological Sciences, vol. 62, pp. 134-142, 1963.

[2] W. Brutsaert, "A generalized complementary principle with physical constraints for land-surface evaporation," Water Resources Research, vol. 51, no. 10, pp. 8087-8093, 2015. 
[3] C. Liu and Y. Zeng, "Changes of pan evaporation in the recent 40 years in the Yellow River Basin," Water International, vol. 29, no. 4, pp. 510-516, 2004.

[4] Y. Zeng, X. Qiu, and C. Liu, "Distributed modeling of evapotranspiration in the Yellow River basin," Advances in Water Science and Technology, vol. 25, pp. 632-640, 2014.

[5] C. Xu, L. Gong, T. Jiang, D. Chen, and V. Singh, "Analysis of spatial distribution and temporal trend of reference evapotranspiration and pan evaporation in Changjiang (Yangtze River) catchment," Journal of Hydrology, vol. 327, no. 1-2, pp. 81-93, 2006.

[6] W. Brutsaert and H. Stricker, "An advection-aridity approach to estimate actual regional evapotranspiration," Water Resources Research, vol. 15, no. 2, pp. 443-450, 1979.

[7] F. I. Morton, "Operational estimates of areal evapotranspiration and their significance to the science and practice of hydrology," Journal of Hydrology, vol. 66, no. 1-4, pp. 1-76, 1983.

[8] R. J. Granger and D. Gray, "Evaporation from natural nonsaturated surfaces," Journal of Hydrology, vol. 111, no. 1-4, pp. 21-29, 1989.

[9] D. Jian, X. Li, H. Tao, J. Huang, and B. Su, "Spatio-temporal variation of actual evapotranspiration and its influence factors in the Tarim River basin based on the complementary relationship approach," Journal of Glaciology and Geocryology, vol. 38, pp. 750-760, 2016.

[10] S. Han, H. Hu, and F. Tian, "Evaluation of applicability of three evapotranspiration models using meteorological data," Journal of Hydraulic Engineering, vol. 40, pp. 75-81, 2009.

[11] S. Han, H. Hu, and F. Tian, "A nonlinear function approach for the normalized complementary relationship evaporation model," Hydrological Processes, vol. 26, no. 26, pp. 3973-3981, 2012.

[12] R. Crago, J. Szilagyi, R. Qualls, and J. Huntington, "Rescaling the complementary relationship for land surface evaporation," Water Resources Research, vol. 52, no. 11, pp. 8461-8471, 2016.

[13] J. Szilagyi, R. Crago, and R. Qualls, "A calibration-free formulation of the complementary relationship of evaporation for continental-scale hydrology," Journal of Geophysical Research: Atmospheres, vol. 122, no. 1, pp. 264-278, 2017.

[14] H. Wang, X. Liu, and G. Li, Soil Environmental Sciences, Higher Education Press, Beijing, China, 2007.

[15] H. L. Penman, "Natural evaporation from open water, bare soil and grass," Proceedings of the Royal Society of London A: Mathematical, Physical and Engineering Sciences, vol. 193, no. 1032 , pp. $120-145,1948$.

[16] H. L. Penman, "Estimating evaporation," Transactions, American Geophysical Union, vol. 37, no. 1, pp. 43-50, 1956.

[17] C. Priestley and R. Taylor, "On the assessment of surface heat flux and evaporation using large-scale parameters," Monthly Weather Review, vol. 100, no. 2, pp. 81-92, 1972.

[18] P. S. Eagleson, Ecohydrology: Darwinian Expression of Vegetation Form and Function, Cambridge University Press, Cambridge, UK, 2005.

[19] X. Qiu, Y. Zeng, and C. Liu, "A study on actual evaporation from non-saturated surfaces," Progress in Human Geography, vol. 22, pp. 118-124, 2003.

[20] A. L. Flint and S. W. Childs, "Use of the Priestley-Taylor evaporation equation for soil water limited conditions in a small forest clearcut," Agricultural and Forest Meteorology, vol. 56, no. 3-4, pp. 247-260, 1991.

[21] R. G. Allen, L. S. Pereira, D. Raes, and M. Smith, Crop Evapotranspiration-Guidelines for Computing Crop Water
Requirements-FAO Irrigation and Drainage Paper 56, FAO, Rome, Italy, 1998.

[22] Y. Zeng, Distributed Modeling of Actual Evapotranspiration in the Yellow River Basin, Chinese Academy of Sciences, Beijing, China, 2004.

[23] J. A. Valiente, M. Nunez, E. Lopez-Baeza, and J. F. Moreno, "Narrow-band to broad-band conversion for Meteosat-visible channel and broad-band albedo using both AVHRR-1 and -2 channels," International Journal of Remote Sensing, vol. 16, no. 6, pp. 1147-1166, 1995.

[24] J. H. Joseph, W. Wiscombe, and J. Weinman, "The deltaEddington approximation for radiative flux transfer," Journal of the Atmospheric Sciences, vol. 33, no. 12, pp. 2452-2459, 1976.

[25] A. Skartveit, J. A. Olseth, and M. E. Tuft, "An hourly diffuse fraction model with correction for variability and surface albedo," Solar Energy, vol. 63, no. 3, pp. 173-183, 1998.

[26] X. Zhu, X. Qiu, Y. Zeng et al., "Effects of complex terrain on net surface longwave radiation in China," Theoretical and Applied Climatology, pp. 1-14, 2017.

[27] X. Li, Spatio-Temporal Variation of Actual Evaporation in the Pearl, Haihe and Tarim River Basins of China, Nanjing University of Information Science and Technology, Nanjing, China, 2013.

[28] R. H. McCuen, “A sensitivity and error analysis of procedures used for estimating evaporation," Journal of the American Water Resources Association, vol. 10, no. 3, pp. 486-497, 1974.

[29] K. Beven, "A sensitivity analysis of the Penman-Monteith actual evapotranspiration estimates," Journal of Hydrology, vol. 44, no. 3-4, pp. 169-190, 1979.

[30] F. Hupet and M. Vanclooster, "Effect of the sampling frequency of meteorological variables on the estimation of the reference evapotranspiration," Journal of Hydrology, vol. 243, no. 3-4, pp. 192-204, 2001.

[31] T. Lenhart, K. Eckhardt, N. Fohrer, and H.-G. Frede, "Comparison of two different approaches of sensitivity analysis," Physics and Chemistry of the Earth, Parts $A / B / C$, vol. 27, no. 9-10, pp. 645-654, 2002.

[32] Y. Yin, S. Wu, G. Chen, and E. Dai, "Attribution analyses of potential evapotranspiration changes in China since the 1960s," Theoretical and Applied Climatology, vol. 101, no. 1-2, pp. 19-28, 2010. 

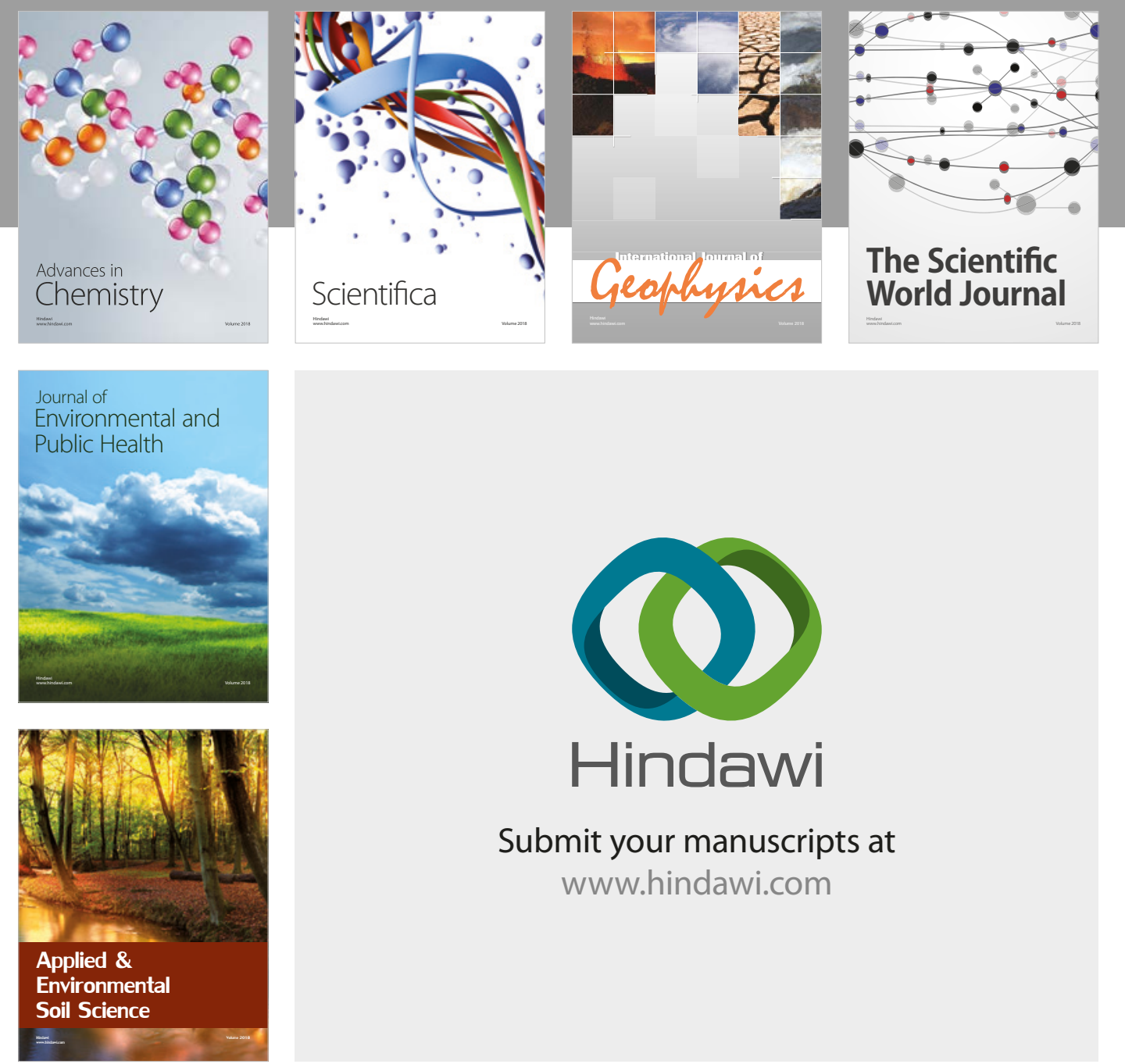

The Scientific

\section{World Journal}
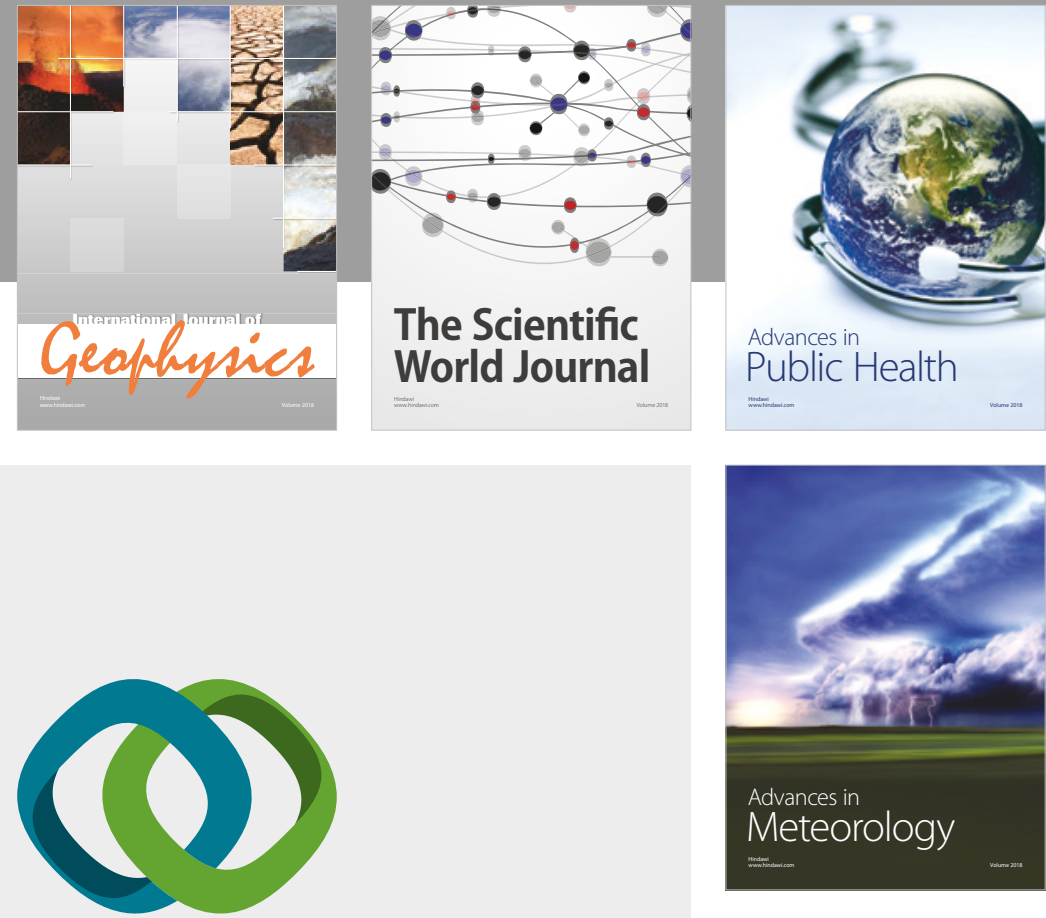

Advan

Public Health

\section{Hindawi}

Submit your manuscripts at

www.hindawi.com
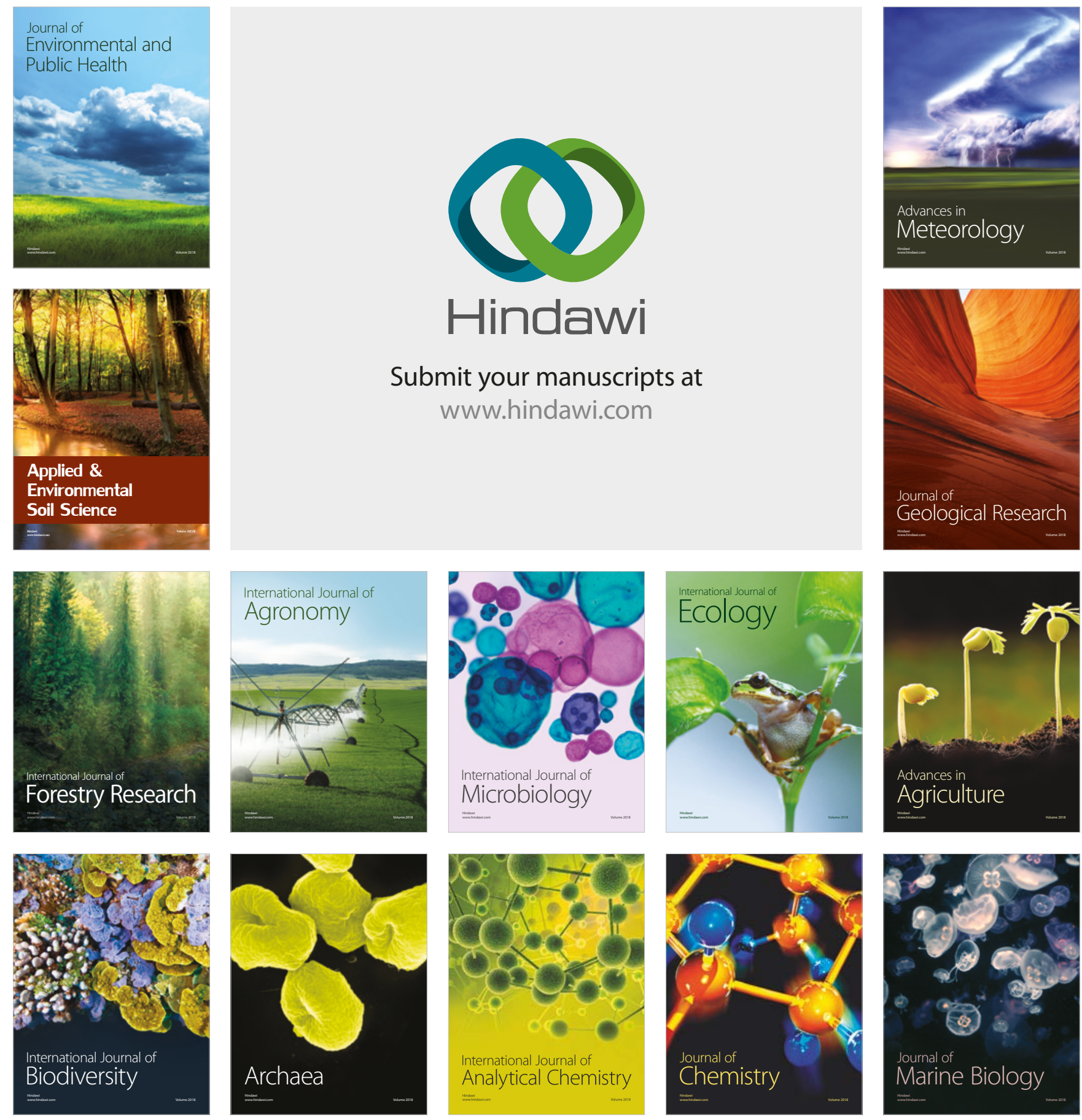